\title{
A!
}

This is an electronic reprint of the original article.

This reprint may differ from the original in pagination and typographic detail.

Honkapohja, Seppo; Mitra, Kaushik

\section{Price level targeting with evolving credibility}

Published in:

JOURNAL OF MONETARY ECONOMICS

DOI:

10.1016/j.jmoneco.2019.09.009

Published: 01/12/2020

Document Version

Publisher's PDF, also known as Version of record

Published under the following license:

CC BY-NC-ND

Please cite the original version:

Honkapohja, S., \& Mitra, K. (2020). Price level targeting with evolving credibility. JOURNAL OF MONETARY ECONOMICS, 116, 88-103. https://doi.org/10.1016/j.jmoneco.2019.09.009

This material is protected by copyright and other intellectual property rights, and duplication or sale of all or part of any of the repository collections is not permitted, except that material may be duplicated by you for your research use or educational purposes in electronic or print form. You must obtain permission for any other use. Electronic or print copies may not be offered, whether for sale or otherwise to anyone who is not an authorised user. 


\title{
Price level targeting with evolving credibility
}

\author{
Seppo Honkapohja a ${ }^{a}$ Kaushik Mitra ${ }^{\mathrm{b}, \mathrm{c}, *}$ \\ a Aalto University School of Business, Finland \\ ${ }^{\mathrm{b}}$ University of Birmingham, United Kingdom

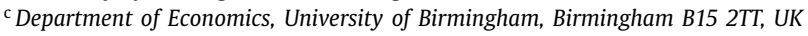

\section{A R T I C L E I N F O}

\section{Article history:}

Received 18 May 2018

Revised 2 September 2019

Accepted 9 September 2019

Available online 13 September 2019

\section{JEL classification:}

E63

E52

E58

Keywords:

Adaptive learning

Limited credibility

Inflation targeting

Zero interest rate lower bound

\begin{abstract}
A B S T R A C T
$\overline{\text { Global learning dynamics for price-level targeting (PLT) monetary policy are analyzed and }}$ compared to inflation targeting in a nonlinear New Keynesian model. Domain of attraction of target steady state is a new robustness criterion for policy regimes. Robustness of PLT depends on whether a known target path is incorporated into learning. Credibility is measured by accuracy of this forecasting method relative to simple statistical forecasts evolving through reinforcement learning. Initial credibility and target price are key factors influencing performance. Model results are in line with the Swedish experience of price stabilization in1930's.
\end{abstract}

(C) 2019 The Authors. Published by Elsevier B.V. This is an open access article under the CC BY-NC-ND license. (http://creativecommons.org/licenses/by-nc-nd/4.0/)

\section{Introduction}

The view that inflation targeting (IT) is a robust monetary policy framework was shaken by the global financial crisis in 2007-8 resulting in policy interest rates stuck near zero levels for a very long time in the US and Europe. An earlier crisis in Japan had led to very low rates since the mid 1990s. This so-called zero lower bound (ZLB) constraint for policy interest rates has raised calls from prominent central bankers to reform the monetary policy framework. Price level targeting (PLT) has been suggested as a more appropriate framework for monetary policy than IT. Evans (2012) discusses how PLT provides additional guidance and can be used to combat the liquidity trap and Carney (2012) remarks that with policy rates at ZLB "there could be a more favorable case for nominal GDP targeting" (nominal GDP targeting is related to PLT).

More recently, Williams (2017), President of the FRB of New York and (Bernanke, 2017), former Chairman of the US Federal Reserve, have come out forcefully in support of flexible PLT. While Williams suggests that flexible PLT would be a good monetary policy framework in a world with a low natural rate of interest, Bernanke recommends it as the best policy

\footnotetext{
He gratefully acknowledge useful comments by the Editor, an anonymous referee, Klaus Adam, James Bullard, George Evans, Bruce McGough, Patrick Pintus, Bruce Preston, John Williams, Michael Woodford and participants in various seminars. Helpful advice from Peyton Young (about reinforcement learning), Lars Jonung and Juha Tarkka (about the Swedish experience), Anindya Banerjee, Ioannis Karavias, Pei Kuang and Markku Lanne are also acknowledged. We specially thank Ioannis Karavias for his help with Appendix E2. Honkapohja is grateful for research funding from the Yrjö Jahnsson Foundation. Any views expressed are those of the authors and do not necessarily reflect the views of the Bank of the Finland, where the first author worked while the research was partly done.

* Corresponding author at: University of Birmingham, United Kingdom.

E-mail address: k.mitra@bham.ac.uk (K. Mitra).
} 
in times when short term interest rates are near zero. Bernanke advocates temporary PLT as an alternative framework for monetary policy (and against a higher inflation target under IT). (Bullard, 2018) and (Bostic, 2018), Presidents of the FRB of Saint Louis and Atlanta respectively, suggest PLT should be studied further.

Despite the strong advocacy, there is in fact very little actual experience with PLT. Historically, the closest example to our knowledge is Sweden which in the 1930s practiced monetary policy akin to PLT for about two years; see Jonung (1979) and Berg and Jonung (1999) for a detailed study. This probably explains why PLT analysis has been mostly confined to the academic literature, which has typically relied on the rational expectations (RE) hypothesis. This paper relaxes the RE assumption and analyzes PLT as a monetary policy framework under imperfect knowledge and compares it to IT. Our perspective is in line with the recent comprehensive survey paper on monetary policy by Eusepi and Preston (2018).

The key novelty in this paper is that performance of PLT is assessed in the presence of endogenously evolving credibility of PLT monetary policy, taking into account the self-referential feature of the model. The evolution of credibility is formally modeled as reinforcement learning on the part of agents. The main question is whether introduction of PLT in the presence of ZLB and sluggish economic activity can induce the economy to escape from the recession scenario towards the desired steady state.

The analysis is conducted in a non-linear micro-founded New Keynesian (NK) model where the ZLB on interest rates is explicitly taken into account. The PLT regime, like IT, is subject to global indeterminacy problems as the ZLB creates two steady states, the targeted steady state and a low-inflation ("liquidity trap") steady state at which the policy interest rate is at the ZLB. This paper elucidates circumstances conducive to a successful escape from the ZLB regime by focusing on different possibilities in the announced aspects of PLT and its evolving credibility. To obtain the results and intuition as stark as possible the NK model is kept simple in other respects e.g. by ignoring financial market frictions. One interpretation of the analysis is that financial frictions leading to appearance of a credit spread have caused the economy to be stuck in a deflationary (low inflationary) scenario. ${ }^{1}$

Interestingly, the dynamics of a calibrated version of the model fits the Swedish experience with price stabilization in the 1930s. To our knowledge, this is the first paper to make theoretical arguments for PLT that accord with the Swedish experience.

Dynamic performance of learning in the PLT regime strongly depends on nature of communication about the target price path in PLT and the degree of credibility of the regime. A basic issue in a move from IT to PLT is whether a future target path for the price level should be announced. If the target path is made known, the significance of additional guidance about the future depends on how much weight this information has in the agents' forecasts for inflation. Private agents can combine inflation forecasts based on knowledge about the target price path with forecasts based purely on inflation data. The weight of the former forecasts relative to the latter measures credibility of PLT in our case. Credibility is assumed to evolve endogenously over time depending on the relative performance measure.

Robustness of monetary policy regimes is assessed by comparing the sizes of the domain of attraction of the targeted steady state under learning for each policy regime. ${ }^{2}$ A large domain of attraction means that the economy will eventually get back to the target even after a large shock. An initial condition away from the targeted steady state may represent a shock to the economy. Domains of attraction have been computed for a given policy regime in the literature, but to our knowledge its size for different regimes has not been used as a desideratum.

The plan of the paper is as follows. Sections 2 and 3 describe the basic model and the equilibrium equations with learning. Section 4 considers the case when the target price level path is not communicated under PLT. Section 5 analyzes the case of full credibility of PLT. The main focus is on imperfect initial credibility of a newly introduced PLT policy which is studied in Section 6. In Section 7 it is shown that a calibrated version of the model can match the experience of Sweden in overcoming deflation during the1930/s episode. Sensitivity analysis for different calibrations of model parameters is also done here. Section 8 concludes. The Online Appendix discusses the literature, intuitions, various technical details, and further aspects of the model dynamics. The beginning of the Appendix lists its sections and the material in them.

\section{A new Keynesian model}

A standard New Keynesian model is employed as the analytical framework (see e.g. Benhabib et al., 2014) but the cashless limit is adopted for simplicity. Many technical details and discussions of the literature are in Online Appendices to this paper.

There is a continuum of household-firms that produce a differentiated consumption good under monopolistic competition and price-adjustment costs. There is a government that uses monetary policy, buys a fixed amount of output and finances spending by taxes and issues of public debt. ${ }^{3}$

\footnotetext{
${ }^{1}$ A positive credit spread due to financial frictions can imply a positive lower bound on market rates, see eg. Curdia and Woodford (2010). Even slightly negative policy rates have been seen recently. For brevity, we do not consider these possibilities.

${ }^{2}$ Formally, the domain of attraction is the set of all initial conditions from which learning dynamics converge to the steady state.

${ }^{3}$ Monetary policy is conducted in terms of a interest rate rule and consumers are assumed to be Ricardian.
} 
The objective for agent $s$ is to maximize expected, discounted isoelastic cum quadratic utility subject to a standard flow budget constraint (in real terms) over the infinite horizon:

$$
\begin{aligned}
& \operatorname{Max} E_{0, s} \sum_{t=0}^{\infty} \beta^{t}\left[\frac{c_{t, s}^{1-\sigma}}{1-\sigma}-\frac{h_{t, s}^{1+\varepsilon}}{1+\varepsilon}-\frac{\gamma}{2}\left(\frac{P_{t, s}}{P_{t-1, s}}-1\right)^{2}\right] \\
& \text { st. } c_{t, s}+b_{t, s}+\Upsilon_{t, s}=R_{t-1} \pi_{t}^{-1} b_{t-1, s}+\frac{P_{t, s}}{P_{t}} y_{t, s},
\end{aligned}
$$

where $c_{t, s}$ is the consumption aggregator, $h_{t, s}$ is the labor input into production, and $b_{t, s}$ denotes the real quantity of risk-free one-period nominal bonds held by the agent at the end of period $t$. $\Upsilon_{t, s}$ is the lump-sum tax collected by the government, $R_{t-1}$ is the nominal interest rate factor between periods $t-1$ and $t, P_{t, s}$ is the price of consumption good $s, y_{t, s}$ is output of good $s, P_{t}$ is the aggregate price level, and the inflation rate is $\pi_{t}=P_{t} / P_{t-1}$. The subjective discount factor is denoted by $\beta$. The parameters $\sigma, \varepsilon, \gamma>0$.

The final term parameterizes the cost of adjusting prices in the spirit of Rotemberg (1982). The Rotemberg formulation is used rather than the Calvo model of price stickiness because it enables us to study global dynamics in the nonlinear system. The household decision problem is also subject to the usual "no Ponzi game" (NPG) condition. In (1) the expectations $E_{0, s}($.) are in general subjective and may not be rational. This approach is called anticipated utility maximization over the infinite horizon (IH).

Production function for good $s$ is standard $y_{t, s}=h_{t, s}^{\alpha}$, where $0<\alpha<1$. There is no capital. Output is differentiated and firms operate under monopolistic competition. Each firm faces a downward-sloping demand curve

$$
P_{t, s}=\left(\frac{y_{t, s}}{y_{t}}\right)^{-1 / v} P_{t} .
$$

Here $P_{t, s}$ is the profit maximizing price set by firm $s$ consistent with its production $y_{t, s}$. The parameter $v$ is the elasticity of substitution between two goods and is assumed to be greater than one. $y_{t}$ is aggregate output, which is exogenous to the firm.

The market clearing condition is $c_{t}+g_{t}=y_{t}$. The government consumes amount $g_{t}$ of the aggregate good, collects the real lump-sum tax $\Upsilon_{t}$ from each consumer and issues bonds $b_{t}$ to cover financing needs. Fiscal policy is assumed to follow a linear tax rule for lump-sum taxes $\Upsilon_{t}=\kappa_{0}+\kappa b_{t-1}$, where $\beta^{-1}-1<\kappa<1$, so fiscal policy is "passive" in Leeper (1991) terminology. Government purchases $g_{t}$ is taken to be stochastic, so that $g_{t}=\bar{g}+\tilde{g}_{t}$, where the random part $\tilde{g}_{t}$ is an observable exogenous AR process

$$
\tilde{g}_{t}=\rho \tilde{g}_{t-1}+v_{t}
$$

with zero mean. ${ }^{4}$

\subsection{The Phillips curve and the consumption function}

To determine the infinite-horizon (nonlinear) Phillips curve, the following assumptions are made for reasons of simplicity (see Benhabib et al., 2014 for further details). It is assumed that agents have identical utility and production functions. Initial debt holding and prices are also assumed to be identical. In addition, it is assumed that (i) agents have homogenous point expectations and (ii) have learnt the per capita market clearing equation from past experience. In this representative agent economy temporary equilibrium in current period $t$ has the property $P_{t, s}=P_{t}$ for all product varieties. As harmless simplification it is assumed that $P_{t+j, s}^{e}=P_{t+j}^{e}$ for expectations.

It can be shown that the Phillips curve takes the form

$$
\begin{aligned}
Q_{t}= & \tilde{K}\left(y_{t}, y_{t+1}^{e}, y_{t+2}^{e} \ldots\right) \equiv \frac{v}{\alpha \gamma} y_{t}^{(1+\varepsilon) / \alpha}-\frac{v-1}{\gamma} \frac{y_{t}}{\left(y_{t}-\left(\bar{g}+\tilde{g}_{t}\right)\right)^{\sigma}} \\
& +\frac{v}{\gamma} \sum_{j=1}^{\infty} \alpha^{-1} \beta^{j}\left(y_{t+j}^{e}\right)^{(1+\varepsilon) / \alpha}-\frac{v-1}{\gamma} \sum_{j=1}^{\infty} \beta^{j} \frac{y_{t+j}^{e}}{\left(y_{t+j}^{e}-\left(\bar{g}+\rho^{j} \tilde{g}_{t}\right)\right)^{\sigma}},
\end{aligned}
$$

where the notation $Q_{t}=\left(\pi_{t}-1\right) \pi_{t}$ is used. Expectations in (5) are formed at time $t$ and based on parameter estimates that use information about endogenous variables at the end of period $t-1$. Actual variables and the observable exogenous random shock at time $t$ are assumed to be known when agents make current decisions. Eq. (5) is treated as one of temporary equilibrium equations that determine $\pi_{t}$, given expectations $\left\{y_{t+j}^{e}\right\}_{j=1}^{\infty} .^{5}$

\footnotetext{
${ }^{4}$ For simplicity, it is assumed $\rho$ is known (if not it could be estimated during learning). Only one shock is introduced in order to have a simple exposition of the basics of least squares learning and endogenous dynamics. No attempt is made to obtain a good fit using a variety of random shocks. For the latter see e.g. Amano and Shukayev (2012).

${ }^{5}$ Note that expected future aggregate inflation rate does not directly affect current inflation but there is an indirect effect via current output in the Phillip's curve (5). Using (3) in the first-order conditions to eliminate relative prices and the representative agent assumption, each firm's output equals average output in every period. Since firms can be assumed to have learned this to be the case, we obtain (5).
} 
To derive the consumption function it is assumed that consumers are Ricardian in the sense that they amalgamate their own intertemporal budget constraint and that of the governments (where the latter is evaluated at price expectations of the consumer). It can be shown the consumption function takes the form

$$
c_{t} \sum_{j=1}^{\infty} \beta^{j / \sigma}\left(D_{t, t+j}^{e}\right)^{(1-\sigma) / \sigma}=\sum_{j=1}^{\infty}\left(D_{t, t+j}^{e}\right)^{-1}\left(y_{t+j}^{e}-\left(\bar{g}+\rho^{j} \tilde{g}_{t}\right)\right),
$$

where the discount factor is

$$
D_{t, t+j}^{e}=\frac{R_{t}}{\pi_{t+1}^{e}} \prod_{i=2}^{j} \frac{R_{t+i-1}^{e}}{\pi_{t+i}^{e}} .
$$

In practice central banks do not make their policy instrument rules known; thus we assume agents do not know the interest rule or even its functional form (this is often called the non-transparent case). This is reflected in (7) by private agents forming expectations about future interest rates. ${ }^{6}$

\subsection{Monetary policy frameworks}

\subsubsection{Inflation targeting (IT)}

For simplicity of comparison, IT is modeled using the standard Taylor rule that is piecewise linear

$$
R_{t}=1+\max \left[\bar{R}-1+\psi_{\pi}\left(\pi_{t}-\pi^{*}\right)+\psi_{y}\left[\left(y_{t}-y^{*}\right) / y^{*}\right], 0\right],
$$

where $\bar{R}=\beta^{-1} \pi^{*}$ is the gross interest rate at the target and the ZLB is introduced, so that the gross interest rate cannot fall below one. Target output $y^{*}$ is the steady state value associated with $\pi^{*}$. The inflation target $\pi^{*}$ for the medium-long run is assumed to be known to private agents but agents do not know the rule (8).

\subsubsection{Price-level targeting (PLT)}

A simple formulation is considered, where (i) the policy maker sets an exogenous target path for the price level $\left\{\bar{P}_{t}\right\}$ as a medium to long run target and (ii) sets the policy instrument with the intention to move the actual price level gradually toward a targeted price level path.

The target path $\left\{\bar{P}_{t}\right\}$ is assumed to involve constant inflation, so that

$$
\bar{P}_{t} / \bar{P}_{t-1}=\pi^{*} \geq 1 \text {. }
$$

The interest rate is set according to the Wicksellian rule

$$
R_{t}=1+\max \left[\bar{R}-1+\psi_{p}\left[\left(P_{t}-\bar{P}_{t}\right) / \bar{P}_{t}\right]+\psi_{y}\left[\left(y_{t}-y^{*}\right) / y^{*}\right], 0\right]
$$

where the max operation takes account of the ZLB. To have comparability to the IT rule (8), a piecewise linear formulation and the same level for target inflation are adopted. Rules like (10) are called Wicksellian, see pp. 260-61 of (Woodford, 2003) and (Giannoni, 2014). ${ }^{7}$ Here the interest rate is set above (below) the targeted steady-state value of the instrument when the actual price level is above (below) the targeted price-level path $\bar{P}_{t}$, measured in percentage deviations. A response to the percentage gap between targeted and actual levels of output is also allowed. This formulation could be called flexible price-level targeting.

In the PLT regime the policy maker may or may not announce the target path $\left\{\bar{P}_{t}\right\}$ for the price level. (i) The case of PLT with opacity arises if $\left\{\bar{P}_{t}\right\}$ is not made known to the private agents. In this case agents continue to forecast inflation using only past data on inflation (and other observable variables). ${ }^{8}$ (ii) The target path $\left\{\bar{P}_{t}\right\}$ is announced to agents. There is full credibility if agents make full use of the announced target price level path in inflation forecasting and place no weight on pure statistical forecasting from inflation data (details are discussed below).

The general case is imperfect credibility, where private agents are assumed to form their inflation forecasts as a weighted average of the forecasts based on preceding cases of (i) and (ii) above. Use of the relative weights of the two forecasting methods measures the degree of credibility and modeling this evolution of limited credibility as endogenous over time are the crucial elements in our analysis.

\section{Learning and temporary equilibrium}

In adaptive learning it is assumed that each agent has a model for perceived dynamics of state variables, also called the perceived law of motion (PLM), to make their forecasts. In any period the PLM parameters are estimated by recursive least

\footnotetext{
6 The implications of transparency are available in earlier versions of this paper.

7 PLT is sometimes advocated as a way to achieve optimal policy with timeless perspective under RE locally near the targeted steady state. The learnability properties then depend on the implementation of the corresponding interest rate rule. See (Evans and Honkapohja, 2013), section 2.5.2 for an overview and further references.

8 This assumption is plausible as lacking any prior experience of PLT, agents might forecast inflation the same way they did under IT.
} 
squares using available data and the estimated model is used for forecasting. The PLM parameters are re-estimated when new data becomes available in the next period. A common formulation is to postulate that the PLM is a linear regression model where endogenous variables depend on intercepts, observed exogenous variables and (possibly) lags of endogenous variables. Then estimation would be based on least squares or related methods. ${ }^{9}$

In the current model agents' learning is about how to forecast future inflation, output and interest rate. The model is purely forward-looking while the observable exogenous shock $\tilde{g}_{t}$ is an AR(1) process. Then the appropriate PLM is a linear projection of $\left(y_{t+1}, \pi_{t+1}, R_{t+1}\right)$ onto an intercept and the exogenous shock and agents estimate the regressions

$$
s_{u}=a_{s}+b_{s} \tilde{g}_{u-1}+\varepsilon_{s, u},
$$

where $s=y, \pi, R$ by using a version of least squares and data for periods $u=1, \ldots, t-1$. The latter is a common timing assumption in the learning literature; at the end of period $t-1$ the parameters are estimated using data through to period $t-1$. This gives estimates $a_{y, t-1}, b_{y, t-1}, a_{\pi, t-1}, b_{\pi, t-1}, a_{R, t-1}, b_{R, t-1}$ and using these estimates and data at time $t$ the forecasts are given by

$$
s_{t+j}^{e}=a_{s, t-1}+b_{s, t-1} \rho^{j} \tilde{g}_{t},
$$

for future periods $t+j$. These forecasts are then substituted into the system to determine a temporary equilibrium of the economy in periods $t+j$. With the new data point the estimates are updated and the process continues.

It turns out that the technical analysis of convergence and computation of domains of attraction can be carried out using a simplification. The model is purely forward-looking while $\tilde{g}_{t}$ is an AR(1) process. Then the appropriate PLM is a linear projection of the state variables $\left(y_{t+1}, \pi_{t+1}, R_{t+1}\right)$ onto an intercept and the exogenous shock and in this case convergence of learning to a fixed point is fully governed by the dynamics of intercepts. Thus, domains of attraction can be validly computed by assuming $\tilde{g}_{t}$ is identically zero. The agents are then thought to estimate the mean values of state variables, called "steady state learning", and is used here as a technical tool. It is emphasized that in simulations of the full model agents do least squares learning.

Steady state learning with point expectations is formalized as

$$
s_{t+j}^{e}=s_{t}^{e} \text { for all } j \geq 1 \text {, and } s_{t}^{e}=s_{t-1}^{e}+\omega_{t}\left(s_{t-1}-s_{t-1}^{e}\right)
$$

It should be noted that in this notation expectations $s_{t}^{e}$ refer to future periods (and not the current one). When forming $s_{t}^{e}$ the newest available data point is $s_{t-1}$, i.e. expectations are formed in the beginning of the current period. This paper assumes 'constant gain' learning, so that the gain parameter $\omega_{t}=\omega$, for $0<\omega \leq 1$ and assumed to be small.

The temporary equilibrium equations of the model with steady-state learning are: ${ }^{10}$

(i) the aggregate demand function which is obtained by combining the consumption function (6) with the market clearing condition, $c_{t}+g_{t}=y_{t}$,

$$
y_{t}=Y\left(y_{t}^{e}, \pi_{t}^{e}, R_{t}, R_{t}^{e}\right),
$$

(ii) the nonlinear Phillips curve which is obtained by combining the inverse function of $Q_{t}=\left(\pi_{t}-1\right) \pi_{t}$ and $(5)$

$$
\left.\pi_{t}=\Pi\left(y_{t}, y_{t}^{e}\right)\right]
$$

These are coupled with the interest rate rule (10) under PLT (or (8) under IT. With Ricardian consumers, we note that the dynamics for assets do not influence the dynamics of inflation, output and the interest rate.

\section{Expectation dynamics}

\subsection{Steady states and stability}

A non-stochastic steady state $(y, \pi, R)$ under PLT must satisfy the Fisher equation $R=\beta^{-1} \pi$, the interest rate rule (10), and steady-state form of the equations for output and inflation (14) and (15). One steady state clearly obtains when the actual inflation rate equals the inflation rate of the price-level target path, see Eq. (9). Then $R=\bar{R}, \pi=\pi^{*}$ and $y=y^{*}$, where $y^{*}$ is the unique solution to the equation

$$
\left.\pi^{*}=\Pi\left(Y\left(y^{*}, \pi^{*}, \bar{R}, \bar{R}\right), y^{*}\right)\right] .
$$

Moreover, for this steady state $P_{t}=\bar{P}_{t}$ for all $t$.

The targeted steady state under the PLT rule is, however, not unique. Intuitively, the Fisher equation $R=\beta^{-1} \pi$ is a key equation for a nonstochastic steady state and $\bar{R}, \pi^{*}$ satisfies the equation. If policy sets $R=1$, then $\hat{\pi}=\beta<1$ becomes a second steady state as the Fisher equation also holds when the ZLB condition is binding: ${ }^{11}$ Moreover the targeted steady state is locally determinate while the second steady state is locally indeterminate.

\section{Remark 1.}

\footnotetext{
${ }^{9}$ Online Appendix B discusses the setting more, including references to the learning literature.

10 The explicit expressions are given in Online Appendix C.

11 In what follows $\hat{R}=1$ is taken as a steady state equilibrium. In principle, we then need to impose a finite satiation level in money demand or assume that the lower bound is slightly above one, say $\hat{R}=1+\varepsilon$. The latter assumption is used below in the numerical analysis.
} 
(i) If $\beta^{-1} \pi^{*}-1<\psi_{p}$, there exists a ZLB-constrained steady state under the Wicksellian PLT rule (10) in addition to the target steady state. The ZLB-constrained steady state satisfies $\hat{R}=1, \hat{\pi}=\beta$, where $\hat{y}$ solves the equation $\hat{\pi}=$ $\Pi(Y(\hat{y}, \hat{\pi}, 1,1), \hat{y})$.

(ii) The target steady state is locally determinate if $\psi_{p}>0$ and $\psi_{y} \geq 0$. The second steady state is locally indeterminate.

Next we summarize the stability results for steady states in the IT and PLT regimes when future expectations are formed using steady state learning. Consider PLT with opacity. Expectations of output, inflation and the interest rate influence their behavior as is evident from Eqs. (14) and (15). Expectations are given by Eq. (13) for variables $s=y, \pi, R$. The stability results are:

\section{Remark 2.}

(i) IT: The targeted steady state is expectationally stable if $\psi_{\pi}>\beta^{-1}$, provided $\gamma$ is not too large. ${ }^{12}$ The ZLB-constrained steady state is not expectationally stable.

(ii) PLT under opacity: If $\psi_{p}>0$ the target steady state is expectationally stable, provided $\gamma$ is not too large. The ZLBconstrained steady state is not expectationally stable.

\subsection{Robustness of policy with opacity}

Performance of IT and PLT regimes with opacity are now compared using the domains of attraction of the targeted steady state. This situation could happen if after a shift from IT to PLT agents stick with their earlier forecasting practice or because the target path is not made known.

The calibration adopted for a quarterly framework is $\pi^{*}=1.005, \beta=0.99, \alpha=0.7, \gamma=128.21, v=21, \sigma=\varepsilon=1$, and $g=0.2$. The targeted steady state is $y^{*}=0.943254, \pi^{*}=1.005$ and the low steady state is $y_{L}=0.943026, \pi_{L}=0.99$. For policy parameters in the PLT regime, set $\psi_{p}=0.25$ and $\psi_{y}=1$, used by Williams (2010). For the IT rule ( 8 ) the policy parameter values are assumed to be the usual values $\psi_{\pi}=1.5$ and $\psi_{y}=0.5 / 4$.

The calibrations for $\beta, \alpha, g$ and $\pi^{*}$ (equivalent to $2 \%$ annual inflation) are standard. (Gali, 2008), p.52, recommends $\sigma=\varepsilon=1$ as "commonly used values in business cycle literature". To calibrate $\gamma$, we exploit the relation of the Rotemberg and the Calvo models of costly and sticky price adjustments via their reduced form implications for the linearized Phillips curve, as in Keen and Wang (2007). We assume an average frequency of about 9.3 months for price adjustment (the midrange suggested in Nakamura and Steinsson, 2008) which together with a conservatively estimated markup of $5 \%$ of prices over marginal cost (suggested in Basu and Fernald, 1997), which implies $v=21$, yields the benchmark value of $\gamma$ of $128.21 .{ }^{13}$

Sensitivity with respect to initial inflation and output expectations $\pi_{0}^{e}$ and $y_{0}^{e}$, the key state variables, is now studied. Initial conditions on the interest rate $R_{0}$ and its expectations $R_{0}^{e}$ are set at the target value, while initial conditions on actual inflation and output are set at $y_{0}=y_{0}^{e}+0.0001$ and $\pi_{0}=\pi_{0}^{e}+0.0001$. Also set $P_{0} / \bar{P}_{0}=1.003$ under PLT. The model is simulated under (13) for various values of $\pi_{0}^{e}$ and $y_{0}^{e}$. $\pi_{0}^{e}$ ranges from 0.935 to 1.065 at steps of 0.002 while $y_{0}^{e}$ varies from 0.923254 to 0.963254 at steps of 0.0005 (in terms of percentage deviations, output expectations are above and below the target steady state output by around 2\%, which is displayed in Fig. 1). From the numerical analysis one has the result:

Result 1: PLT with opacity is less robust than IT.

Fig. 1 illustrates the result by showing numerically computed domains of attraction for the two rules.

\section{PLT With full credibility}

A publicly made announcement of a target price level path includes useful information for forecasting inflation and thus can change the dynamics of the economy via expectations. A very simple formulation of inflation forecasting that uses data of the gap between actual and target paths of the price level is now introduced. Define the gap variable and an identity

$$
X_{t}=P_{t} / \bar{P}_{t}, X_{t} \equiv X_{t-1} \times\left(\pi_{t} / \pi^{*}\right) .
$$

The identity in (16) is obtained using the definition of the gap and the target path (9).

Future values of gap $X_{t}$ in (16) between the actual and targeted price levels are a natural variable for agents to forecast. The associated expectations of inflation can be inferred from the forecasted gap as follows. Moving the identity in (16) one period forward, the implied inflation forecast can be computed from the equation

$$
{ }_{t} X_{t}^{e} \pi_{t}^{e}=\left(X_{t}^{e} \times \pi^{*}\right),
$$

assuming as before that information on current values of endogenous variables is not available at the time of forecasting. $X_{t}^{e}$ denotes the forecasted value of the gap for the future periods and ${ }_{t} X_{t}^{e}$ refers to the forecast of the current gap $X_{t}$ in the beginning of period $t .^{14}$ Inflation forecasts $\pi_{t}^{e}$ from (17) are then substituted into the aggregate demand function (14).

\footnotetext{
12 This is a version of the Taylor principle. The seminal paper is Bullard and Mitra (2002).

13 Robustness to other calibrations is studied in Section 7.2.

14 Note that ${ }_{t} X_{t+j}^{e}=X_{t}^{e}$ in more detailed notation.
} 

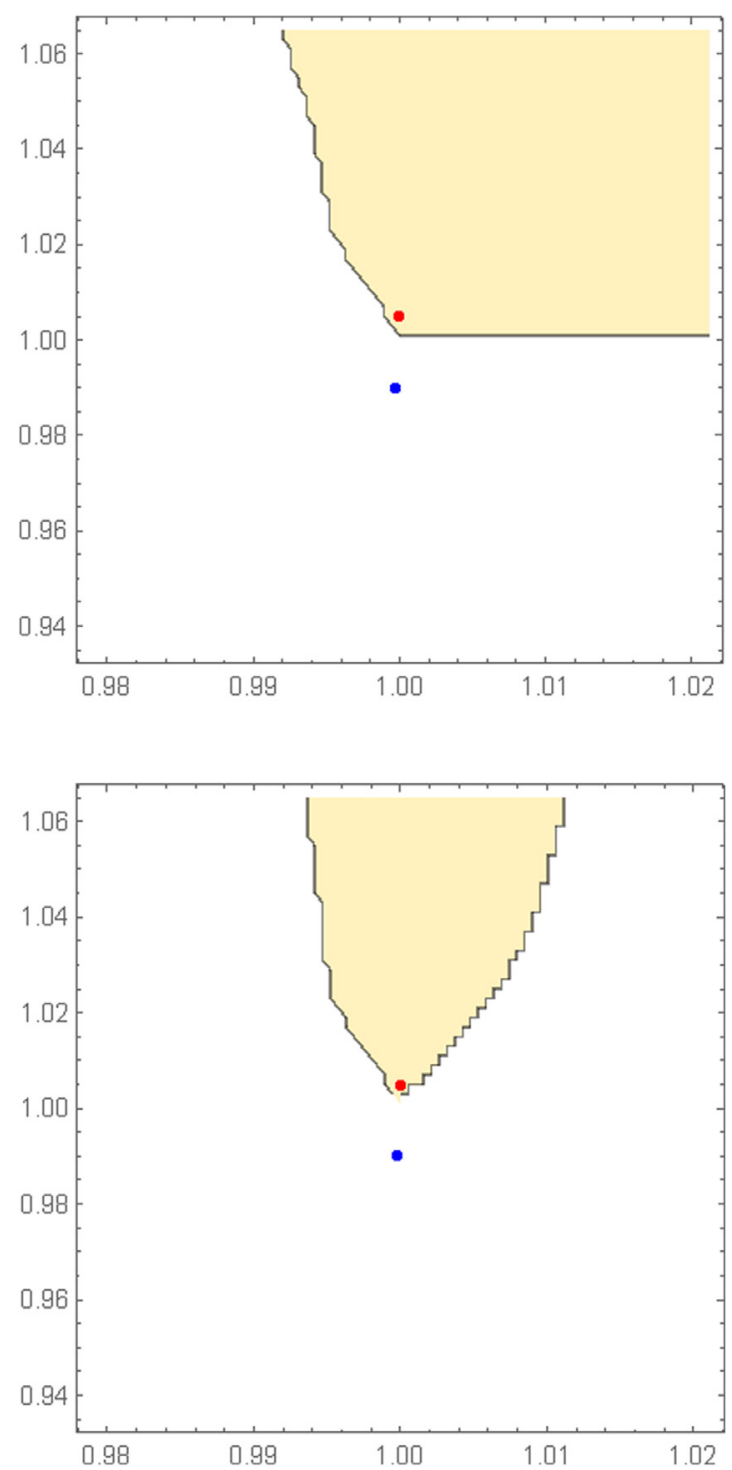

Fig. 1. Domain of attraction for IT (top panel) and that for PLT with opacity (bottom panel). Horizontal axis gives $y_{0}^{e}$ (in deviation from target steady state output) and vertical axis $\pi_{0}^{e}$. Shaded area indicates convergence. The circle in the shaded region denotes the intended steady state and the circle outside the shaded region denotes the unintended steady state.

To compute domains of attraction, the expectations $X_{t}^{e}$ and ${ }_{t} X_{t}^{e}$ are updated using steady-state learning, so that

$$
X_{t}^{e}=X_{t-1}^{e}+\omega\left(X_{t-1}-X_{t-1}^{e}\right)
$$

$$
{ }_{t} X_{t}^{e}=\omega_{1} X_{t-1}+\left(1-\omega_{1}\right) X_{t-1}^{e} \text {, where } \omega_{1}>0 .
$$

Note that ${ }_{t} X_{t}^{e}$ for period $t$ made at the end of $t-1$ is a weighted average of the most recent observation $X_{t-1}$ and the previous forecast $X_{t-1}^{e}$ of the gap for period $t$.

For specifying the values of $\omega$ and $\omega_{1}$ the following considerations seem pertinent. Forecasts $X_{t}^{e}$ are forecasts for the entire future and then the usual assumption in learning models of a quite small $\omega$ seems natural. In contrast, the forecast ${ }_{t} X_{t}^{e}$ is only about the immediate future and then a high weight for the most recent data point $X_{t-1}$ is natural, so that the specification $\omega_{1} \approx 1$ is natural. In the numerics $\omega_{1}=1$ is used but analogous results hold for other values for $\omega_{1}$. Under full 


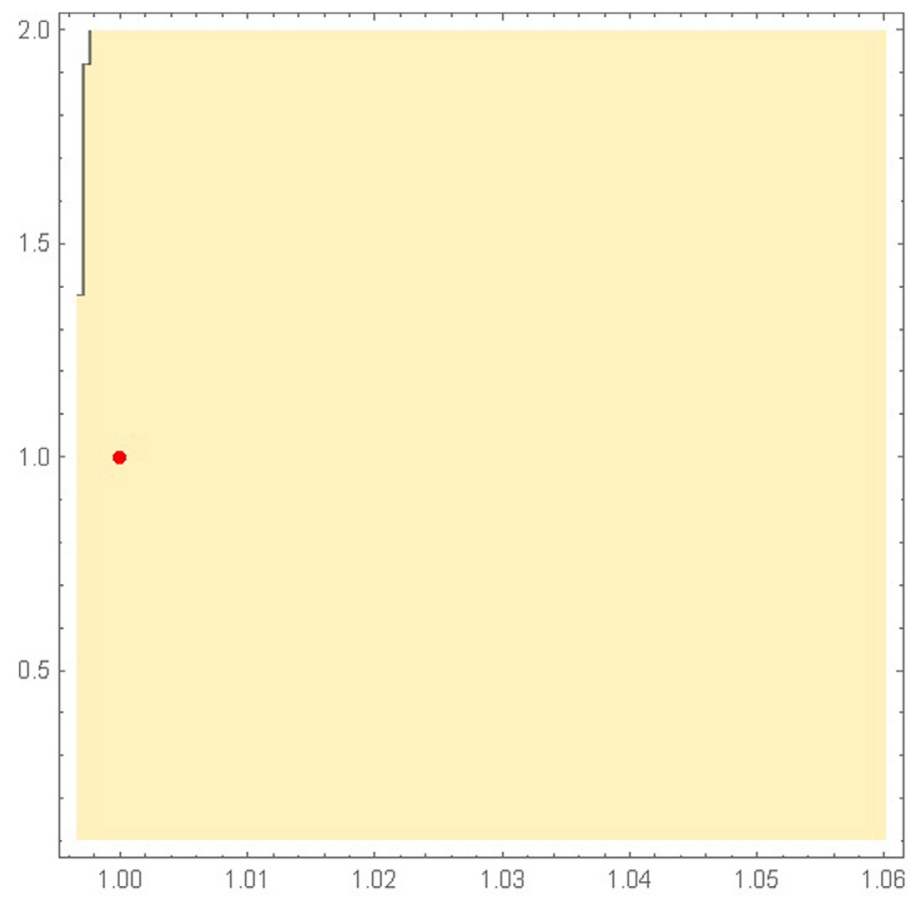

Fig. 2. Domain of attraction for PLT with forecasting of gaps when initial conditions are close to the low steady state. Horizontal axis gives $y_{0}^{e}$ (in deviation from target steady state output) and vertical axis gives $X_{0}^{e}$. The circle represents the targeted steady state. Shaded area indicates convergence.

credibility of PLT the price gap expectations follow (18) and inflation expectations are given by ${ }^{15}$

$$
\pi_{t}^{e}=\left(X_{t}^{e} \times \pi^{*}\right) / X_{t-1}
$$

It must be emphasized that in actual learning dynamics private agents use least squares regression of the type (11) for $s_{t}=X_{t}$ in place of $(18)$.

Given the potential importance of the initial value of the target price path $\bar{P}_{0}$, it is necessary to specify carefully the introduction of the PLT regime in the form of the target path $\left\{\bar{P}_{t}\right\}_{t=0}^{\infty}$, where $\bar{P}_{t} / \bar{P}_{t-1}=\pi^{*}$ and the timing in the initial period. PLT is introduced in the beginning of period 0 as a surprise and the announcement is made after agents have formed their expectations $\pi_{0}^{e}, y_{0}^{e}$ and $R_{0}^{e}$. It is told the policy maker aims to reach the target path in the medium term but no information is given about the interest rate rule. From period 1 onward agents take the regime to be fully credible and use the target price path in their inflation forecasting.

Robustness of PLT policy regime is now analyzed by computing the (partial) domain of attraction for the targeted steady state with focus on sensitivity with respect to displacements of initial output expectations $y_{0}^{e}$ and relative price level expectations $X_{0}^{e}$. Full credibility of PLT has dramatic consequences.

Result 2: The domain of attraction of the target steady state is very large under the PLT rule with full credibility and contains even values for $y_{0}^{e}$ well below the low steady state.

The domain of attraction for PLT with full credibility is thus much larger than that of IT (compare Fig. 1, top panel and Fig. 2).

The calibrations are as before. In the computation, the set of possible initial conditions for $X_{0}^{e}$ and $y_{0}^{e}$ is made large and the initial values of the other variables are at the deflationary steady state $\hat{R}=1.0001, \hat{\pi}=\beta$, and $y=\hat{y}$ are set. Also set $R_{0}=\hat{R}=R_{0}^{e}, \pi_{0}=\hat{\pi}=\pi_{0}^{e}$ and $X_{0}=X_{0}^{e}$. The system is high-dimensional, so only partial domains of attraction can be illustrated. Fig. 2 presents the partial domain of attraction for the PLT policy rule with these initial conditions and wide grids for $y_{0}^{e}$ and $X_{0}^{e}$. The horizontal axis measures $y_{0}^{e}$ and vertical axis $X_{0}^{e}$. The grid search for $y_{0}^{e}$ was over the range 0.94 to 1 at intervals of 0.0005 (in terms of percentage deviations, output expectations are up to $6 \%$ above the target steady state output, which is what is shown in Fig. 2) and that for $X_{0}^{e}$ over the range 0.1 to 2 at intervals of 0.02 .

It is seen that the domain of attraction covers basically the whole area, except the unstable low steady state where $X_{0}=X_{0}^{e}=0 .{ }^{16}$

\footnotetext{
15 Note that output or interest rate expectations do not employ information about the target price level path unless agents have more structural knowledge than is assumed here.

${ }^{16}$ Other simulations have been run for a shock to interest rate expectations $R_{0}^{e}$ with analogous results (details are not reported for reasons of space).
} 
Fig. 2 shows that incorporating fully credible guidance from the PLT path in agents' forecasting can play a key role in moving the economy out of the liquidity trap toward the targeted steady state. It must be emphasized that the preceding set of initial conditions incorporates large pessimistic shocks that have taken the economy to a situation where the ZLB is binding. The mechanism works through resulting deviations of the price level from the target path, i.e., the gap variable $X_{t}$, which influences formation of inflation expectations. A key observation is that if agents have fully incorporated guidance from PLT into their expectations formation, the price level target path continues to influence the economy through inflation expectations even when ZLB is binding.

\section{Evolving credibility ${ }^{17}$}

The result about huge impact of full credibility on the performance of PLT is only an extreme case. Assuming full credibility as soon as the PLT policy is announced is not very plausible. It usually takes time for agents to learn that the new policy performs better than IT. It is, therefore, very important to extend the analysis to cover evolving limited credibility where private agents initially put only some, possibly small weight on the target price path $\left\{\bar{P}_{t}\right\}$ when forecasting inflation.

\subsection{Learning through reinforcement}

This idea is modeled as follows. Agents' forecast of inflation is assumed to be a weighted average of forecasts $\pi_{C, t}^{e}$ and $\pi_{N, t}^{e}$, where $\pi_{C, t}^{e}$ refers to the forecast under full credibility defined by (18)-(20) and $\pi_{N, t}^{e}$ refers to the forecast as a constantgain weighted average of past inflation to capture the no credibility scenario. The weights on $\pi_{C, t}^{e}$ and $\pi_{N, t}^{e}$ are assumed to evolve in accordance with reinforcement learning based on forecast accuracy.

Intuitively, reinforcement is an empirical principle such that the higher the payoff (utility) from taking an action in the past, the higher the likelihood that the action will be taken in the future. A very standard and simple model of reinforcement learning is used. ${ }^{18}$ The analysis is very much a first approach to model evolving credibility and it is acknowledged that alternative formulations could be developed.

Formally, the propensity of each way of forecasting is updated as

$$
\theta_{t}^{C}=\lambda \theta_{t-1}^{C}+u_{t-1}^{C} \text { and } \theta_{t}^{N}=\lambda \theta_{t-1}^{N}+u_{t-1}^{N},
$$

where $\lambda \in(0,1]$. Introduce an auxiliary variable based on the accuracy of forecasting

$$
\tilde{u}_{t}^{C}= \begin{cases}1 & \text { if }\left|\pi_{t}-\pi_{C, t-1}^{e}\right|<\left|\pi_{t}-\pi_{N, t-1}^{e}\right|, \\ 0 & \text { otherwise }\end{cases}
$$

and make the innovation terms in (21) utility weighted. Define the weight for the average forecast and compute the inflation forecast as a weighted average:

$$
\pi_{t}^{e}=q_{t}^{C} \pi_{C, t}^{e}+\left(1-q_{t}^{C}\right) \pi_{N, t}^{e} \text {, where } q_{t}^{C}=\frac{\theta_{t}^{C}}{\theta_{t}^{C}+\theta_{t}^{N}} \text { and } q_{t}^{N}=1-q_{t}^{C} .
$$

Note that the agents' probability of choosing the forecasting scheme corresponding to full credibility, $q_{t}^{C}$, is increasing in the propensity $\theta_{t}^{C}$. Other expectation variables $y_{t}^{e}$ and $R_{t}^{e}$ are updated according to the earlier rules (13). Given these specifications for expectations, the model is the same as before. ${ }^{19}$ In order to run simulations of our model, $\lambda=0.85$ is specified as a numerical value for the decay (or discount) parameter. Other parameters are as above.

\subsection{Robustness with evolving credibility}

Given the very good robustness properties of the PLT policy regime in the extreme case of full credibility (shown in Fig. 2), it is asked whether the same kind of results can hold in the more realistic setting of evolving limited credibility described above. Inflation forecasts are assumed to be given by the combination forecasts (23) and forecast weights are updated in accordance with reinforcement learning.

Since the state space is high dimensional, properties of the domain of attraction are studied by fixing some initial values for the process. In particular, the three variables of interest are $y_{0}^{e}, \pi_{0}^{e}$ and $q_{0}^{C}$, where the dimension of initial inflation expectations is reduced by assuming $\pi_{0}^{e}=\pi_{C, 0}^{e}=\pi_{N, 0}^{e}$. For ease of presentation, the domain of attraction results are presented by fixing one of these variables and varying the remaining two. For the first exercise, fix $y_{0}^{e}$ and vary $\pi_{0}^{e}$ and $q_{0}^{c}$ to plot the partial domain of attraction (see Figure 3).

\footnotetext{
17 Imperfect credibility of monetary policy has been introduced in different ways in the literature. Imperfection is thought to arise, for example, as deviation from RE optimal policy due to the ZLB constraint, see Bodenstein et al. (2012), or from policy maker's doubt about its model in an RE setting, see Dennis (2014), or as weighting of different models but with the weights remaining constant or evolving exogenously, see Coenen and Wieland (2004), Gibbs and Kulish (2017) and Kryvtsov et al. (2008).

18 This is a standard formulation of reinforcement learning in game theory, see e.g. p.13 of Young (2004). See also Chapter 6 of Camerer (2003) for a review of different learning models in game theory.

19 The model with steady state learning is used for computing domains of attraction.
} 
Our interest is to consider the possibility to escape from a state of the economy where ZLB and recession prevail. Output expectations $y_{0}^{e}$ are now fixed at three different values and the initial inflation expectations $\pi_{0}^{e}=\pi_{C, t}^{e}=\pi_{N, t}^{e}$ are varied along with the initial degree of credibility of the PLT policy regime, $q_{0}^{c}$. For each combination $\left(y_{0}^{e}, \pi_{0}^{e}\right)$, the lowest value for $q_{0}^{C}$ of the initial degree of credibility such that the dynamics of learning from this starting point converge to the target steady state is computed numerically. There are three alternative values for $y_{0}^{e}$ : one slightly above the targeted steady state output (by roughly $0.05 \%$ ), the second one at this target level and the third one at the output level corresponding to the low steady state i.e. $y_{0}^{e}=\hat{y}$. A grid of points $\left(q_{0}^{C}, \pi_{0}^{e}\right)$ is then done where the relation between the degree of initial credibility $q_{0}^{C}$ and $\pi_{0}^{e}$ is shown for the different values of $y_{0}^{e}$ indicated above.

Fig. 3 shows the domain of attraction in $\left(q_{0}^{C}, \pi_{0}^{e}\right)$ space when initial output expectation $y_{0}^{e}$ is fixed at the three different initial levels just described. In all of these panels, interest rate expectations are fixed marginally above the ZLB (at 1.0002), to capture the economy being stuck around the ZLB.

In the top panel of Fig. 3, $y_{0}^{e}$ is slightly higher than the level of output at the target steady state. As this figure shows, even deflationary expectations close to $\pi_{0}^{e}=0.9$ (more than $40 \%$ deflation in annual terms!) yield stability with high enough initial credibility. More generally, $\pi_{0}^{e}$ well below the low steady state value $\hat{\pi} \approx \beta$ yields stability even with low credibility. Announcement of PLT with even low credibility suffices to increase the domain of attraction significantly to below zero net inflation levels. (Compare with the domain of attraction shown in the bottom panel of Fig. 1 for the PLT regime with opacity.)

The middle panel of Fig. 3 shows the domain of attraction in $\left(q_{0}^{C}, \pi_{0}^{e}\right)$ space when initial output expectations, $y_{0}^{e}=$ $y^{*}$, i.e. at the target level of output. Note that convergence to the target steady state continues to obtain for deflationary expectations though the values can't be as low as in the top panel. Nevertheless, deflationary expectations (approximately 0.98 which is below the low steady state value $\hat{\pi} \approx \beta$ ) continue to give convergence.

Finally, the bottom panel shows the domain of attraction when initial output expectations, $y_{0}^{e}=\hat{y}$ i.e. at the low steady state output. $\pi_{0}^{e}$ values down to the low steady state value $\hat{\pi} \approx \beta$ continue to give convergence for all values of initial credibility between 0 and 1 (note that $\hat{\pi} \approx \beta$ is $4 \%$ annual deflation, something which is seldom observed). This is particularly striking since initial output expectations are very pessimistic in this figure. In summary:

Result 3: The announcement of the PLT regime coupled with very small initial credibility can make the economy converge back to the targeted steady state from initial conditions with inflation expectations well below the target steady state.

This result is in sharp contrast with the case of the PLT regime with opacity. At first sight limited credibility might be thought as a weighted average of the cases of no and full credibility analyzed before. The full intuition is, however, more complex as the existence of the possibility for forecasting that uses the target price level path influences the actual inflation path which in turn affects also the outcome from simple statistical forecasting. These combined self-referential and feedback effects are the key to Result $3 .^{20}$

Another observation is that higher the initial credibility, $q_{0}^{c}$, larger is the size of the domain of attraction: lower and lower deflation rates may be supported in terms of convergence to the targeted steady state as illustrated by the downward sloping lines of the convergence boundary in the top two panels in Fig. 3 in $\left(q_{0}^{C}, \pi_{0}^{e}\right)$ space. Higher credibility thus has beneficial effects: however, these effects are less evident when initial output expectations are very pessimistic as shown by the nearly horizontal line in the bottom panel of Fig. 3. The message here is that if the policy maker contemplates a move to PLT during a liquidity trap scenario, it should not wait too long since output expectations can then become very pessimistic making it more difficult to get out of this situation.

It is also possible to compare PLT with evolving credibility to the IT regime. It turns out that IT is more robust than PLT when initial inflation expectations are at a high value, but PLT even with low degree of credibility is superior to IT when initial inflation expectations are in the deflationary domain. ${ }^{21}$ With deflationary expectations IT always leads to a deflationary spiral no matter what output expectations are whereas convergence to desired steady state can take place with PLT. PLT is superior in times of binding ZLB and pessimistic inflation/output expectations.

This analysis lends strong support to the suggestions of Evans (2012), Williams (2017) and Bernanke (2017) that guidance from price-level targeting can be very helpful in a liquidity trap. Monetary policy alone is able to pull the economy out of the liquidity trap if PLT can be implemented. It is, however, important to add the qualification that PLT is a good policy only during a liquidity trap scenario.

Result 4: In terms of the robustness criterion (i.e. domain of attraction) PLT is globally a better policy than IT during a deflationary/liquidity trap scenario while IT is the better policy globally during normal times.

\section{Swedish experience with price level targeting}

As noted in the Introduction, Sweden is the only country which has experimented with monetary policy to achieve price level stabilization which is arguably akin to PLT (For details see Jonung 1979 and Berg and Jonung, 1999). In September 1931 the Riksbank and the Swedish government decided to abandon the gold standard and to adopt a new domestic paper

\footnotetext{
20 This intuition and the case of very small degree of initial credibility are discussed in Appendix D.

21 This observation is distinct from the usual criticism of PLT saying that if inflation (and output) are above target and a negative shock hits the economy, the history-dependence of PLT delays the adjustment.
} 

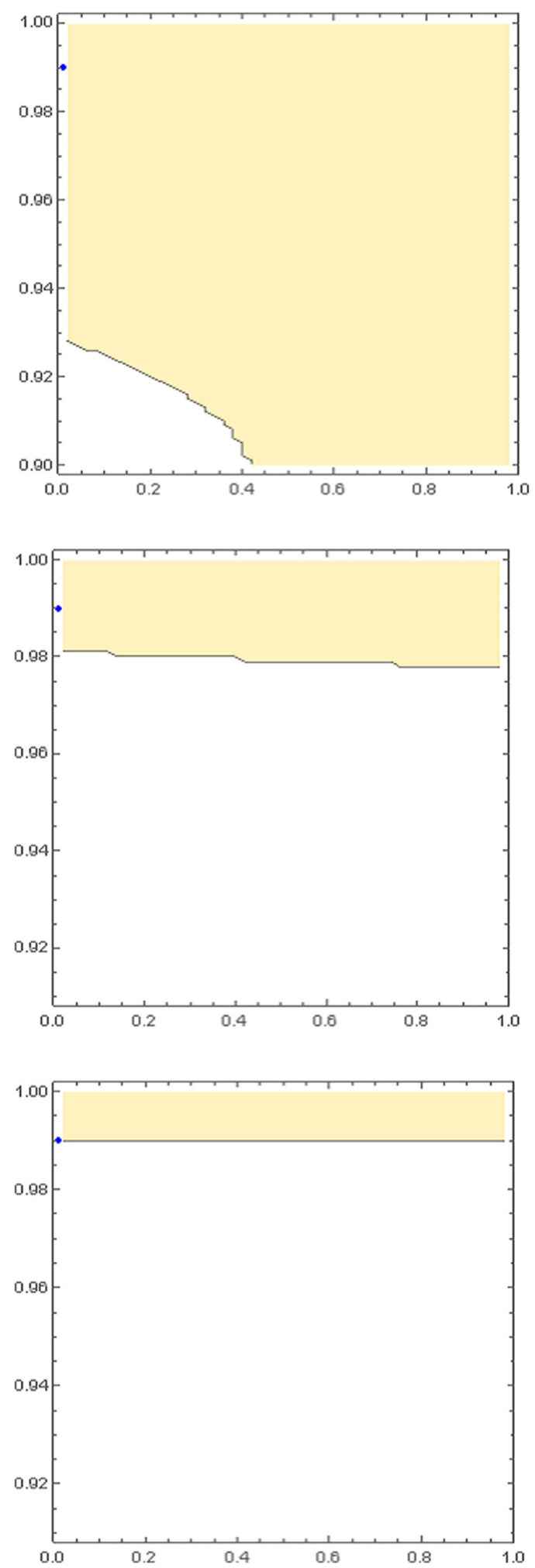

Fig. 3. Domain of attraction for PLT with imperfect credibility corresponding to different levels of initial output expectations: Different degrees of initial credibility $q_{0}^{C}$ are along the horizontal axis and inflation expectations are along the vertical axis. Output expectations are fixed just (0.048\%) above the target steady state output in the top panel, at the target steady state in the middle panel and at the low steady state in the bottom panel. 
Table 1

Moments from the data and model calculated for the two years PLT was in operation for the benchmark case displayed in Fig. 4.

\begin{tabular}{lllllll}
\hline & $\begin{array}{l}\text { Data } \\
\text { Mean }\end{array}$ & $\begin{array}{l}\text { Model } \\
\text { Mean }\end{array}$ & $\begin{array}{l}\text { Data } \\
\text { Std Dev }\end{array}$ & $\begin{array}{l}\text { Model } \\
\text { Std Dev }\end{array}$ & $\begin{array}{l}\text { Data } \\
\text { Autocorr }\end{array}$ & $\begin{array}{l}\text { Model } \\
\text { Autocorr }\end{array}$ \\
\hline$P$ & 98.5577 & 97.9145 & 1.59798 & 1.2793 & 0.619 & 0.639 \\
$R$ & 1.0090 & 1.0064 & 0.00186 & 0.00190 & 0.367 & 0.634 \\
$Y$ & 98.9142 & 100.274 & 0.640023 & 0.155199 & 0.537 & 0.536 \\
\hline
\end{tabular}

standard with the September 1931 price level adopted as the initial target price level in the policy regime. This move was a response to Swedish consumer and wholesale prices that had declined sharply from 1929 up to the first three quarters of 1931. This monetary regime lasted only about two years as Sweden decided in June-July 1933 to peg its currency to Pound Sterling. ${ }^{22}$

This two-year episode of PLT in Sweden took place in the middle of the Great Depression: GDP declined in years 193033 while price deflation which started in 1929 ended in 1934. The policy interest rate declined somewhat from 1930 to the beginning of 1931 and was significantly raised during 1931 Q3 just before the new policy regime started. The rate was gradually brought down from September 1931 to the end of 1933 which contributed to gradual elimination of price deflation.

\subsection{Simulation results}

Time paths from the model are compared to actual data of the price level, interest rate and aggregate output. ${ }^{23}$ The simulations use the calibrated model with evolving credibility described in Sections 2-6. The basic parameters used in the model simulations are mostly the same as in the basic model (see Section 4.2) with the important exceptions that $\pi^{*}=1$, $\psi_{p}=0.15$ and $\psi_{y}=0 . \psi_{y}=0$ is a policy of strict PLT, in line with the Ministry of Finance's announcement (footnote 22), and the value of $\psi_{p}$ is in the mid range of the possible values considered by Williams (2010) (the results are not sensitive to $\psi_{p}$ though). $\pi^{*}=1$ interprets price stability as a zero target inflation rate and the interest rate lower bound in the policy rule is set at $R_{L}=1.001$.

Government fiscal policy is assumed to be constant, except for the random shocks. ${ }^{24}$ The initial conditions are set to be close to the low steady state. As output in the data in 1931 declined, the initial conditions are set at the low steady state $y_{0}=y_{L}$ and $y_{0}^{e}=y_{L}$. As inflation data around 1931 shows very small deflation, $\pi_{N, 0}^{e}$ and $\pi_{N, 0}^{e}$ are slightly below $\pi^{*}$ with actual inflation just below expectations. The price gap and level are set at $X_{0}=1, P_{0}=1$ while $X_{0}^{e}=1$ in line with the start of PLT policy in Sept 1931. Initial interest rate and its expectation are set at $R_{0}=1.015$ and $R_{0}^{e}=1.0106$ which are between the quarterly data points in $1931 \mathrm{Q} 2$ and Q3. Initial credibility is set to $q_{C}^{0}=0.1$ while $\lambda=0.8$. The gain parameter is set at the baseline value of 0.002 and the initial values for PLM parameters are at initial RE values with AR terms set at 0 .

The simulation of the model economy with a Wicksellian PLT rule (10), adapted to Swedish 1931 Q3 initial conditions, is now compared to actual Swedish data for the price level, interest rate and aggregate output in Fig. 4 (which reports the median values from 500 replications of the shock process). The focus is on the period 1931 Q3 to 1933 Q3 when Sweden used PLT. The comparison is continued for a further five years, so that it is possible to see what a Wicksellian PLT policy would have implied for the economy in the longer term, providing a useful counterfactual to the actual Swedish scenario. Fig. 4 shows the time paths of price level, interest rate and output in the simulated economy and corresponding data. Table 1 shows descriptive statistics (mean, standard deviation and first-order autocorrelation) for the variables for the two years of PLT.

We first summarize the main features of the data. The price level is proxied by the quarterly cost of living index. Prices fell over a period of 2 years since September 1931 and rose afterwards till the onset of the Second World War. The data shows sharp declines in interest rates for the two years PLT was in operation and was then subsequently stuck at $2.5 \%$. The fall in the price level and interest rates during 1931 Q3 -1933 Q3 is consistent with a PLT rule (the correlation between these two variables in the data is 0.83 ). Subsequently, the period of fixed interest rates also coincides with the rise in prices till the Second World War.

The output in the model corresponds to GDP; however, GDP data during this period is only available at annual frequency. Data on industrial production is available quarterly but this tends to be very volatile (unlike GDP). The figure shows two

\footnotetext{
22 The Minister of Finance declared that the aim of Swedish monetary policy should be to preserve the domestic purchasing power of the krona using 'all means available'. We note the choice of initial target price level can have significant effects after introduction of price stabilization. This is witnessed by comparing Swedish1930's policy with1920's return to gold standard. See Online Appendix F1 for simulation results.

${ }^{23}$ Our perspective is of adaptive learning which we believe is more plausible for policy changes as considered here for Sweden (see also discussion in Appendix C1, final two paragraphs and footnote 20 of the Appendix). We comment briefly on RE dynamics under the ZLB constraint $R=1$. With IT, the dynamic RE solution paths converge to the liquidity trap steady state or to a limit cycle (see Benhabib, et al., 2001). As near the low steady state the RE paths for PLT are identical to IT, a continuum of convergent RE paths to the liquidity trap steady state exist also under PLT.

24 The autocorrelation coefficient $\rho$ in the government spending process (4) is set to 0.85 with shocks $v_{t}$ generated from a uniform distribution with support $[-0.01,0.01]$. Output at the target and low steady states are $y^{*}=0.911636$ and $y_{L}=0.911467$ here.
} 

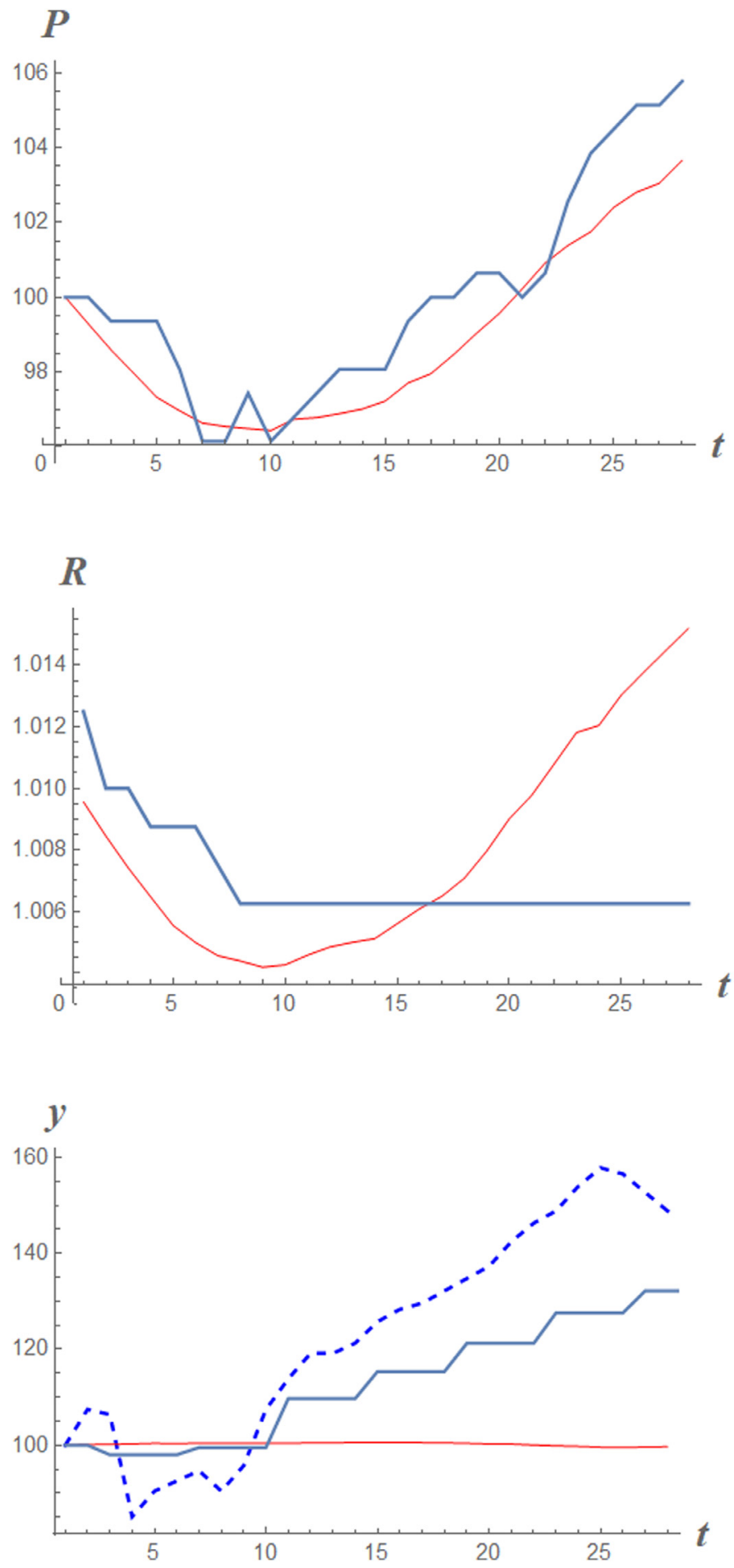

Fig. 4. Top panel: median price level dynamics for the model economy (red curve) and actual price level data from 1931 Q3 to 1938 Q2 (blue curve). The price data is the quarterly cost of living index. Middle panel: simulated median interest rate dynamics (red line) and the actual interest rate data from 1931 Q3 to 1938 Q2 (blue line). Bottom panel: median output dynamics (red line) and actual GDP data (blue line) from 1931 Q3 to 1938 Q2. Only annual data on GDP available which is shown as a step function. The second measure is industrial production shown as the dashed line. Initial output and price level are normalized to 100 while interest rate is at usual quarterly values in the figure. (For interpretation of the references to colour in this figure legend, the reader is referred to the web version of this article.) 
measures of aggregate output: (i) GDP (the annual series is converted to quarterly series through a step increase) and (ii) industrial production. GDP data is relatively stable during the two years of PLT implementation (there is a slight decline followed by a slight rise). Afterwards, however, there are relatively large rises in GDP (and industrial production) till the end of 1930s caused by a variety of factors explained below: these and other considerations noted below may cause difficulties in matching GDP for the model.

Thus, the stylized facts, during the two years PLT was in operation, are the decline in prices and interest rates and the relatively stable path of GDP. We see if our simple benchmark model is able to capture these stylized facts.

Table 1 shows that almost all moments computed from the model are quite close to the corresponding moments in the data providing some evidence the model series behaves similarly to the actual data. ${ }^{25}$ Next we explain the dynamics. Qualitatively, both the cost of living index from the data and the price level index from the model fall during the two year period from September 1931. In fact, magnitudes of the fall during this period are comparable; while the cost of living index falls by $3.85 \%$, the corresponding fall in the price index is by $3.45 \%$. Similarly, interest rate from the data and model both fall during the period. Even quantitatively, these falls are comparable: while the interest rate in the data falls from 1.0125 to 1.00625 (a fall of $0.0062 \%$ ) during the two year period, the corresponding fall in the model interest rate is from 1.0096 to 1.0044 (a fall of $0.0052 \%$ ). Finally, output increases by $0.4 \%$ in the model simulation while GDP falls by $0.47 \%$ during this two year period.

In summary, the model can describe well the central macro aspects of the Swedish experiment with PLT. In particular, the fall in prices and interest rates in the data are well matched by the model, both qualitatively and quantitatively. Even the match for GDP is reasonable (there is not much fluctuation in either model or data for this period).

We briefly compare the model with data after the PLT period. After around two years of PLT, monetary policy regime was radically changed. The Swedish krona was pegged to pound sterling and the central bank adopted a constant policy interest rate for the rest of 1930's. This rate was set at $R=1.00625$ (in quarterly terms) which was a percentage point higher than the corresponding policy rate in the UK. The actual interest rate policy after 1933 Q3 is quite different from the Wicksellian PLT policy implied by the model. The second panel of Fig. 4 shows that in the model the interest rate with Wicksellian policy begins to rise as the economy recovers and converges to the target steady state. ${ }^{26}$ The price level from the model, like the cost of living index in the data, rises over the subsequent five year period and the match continues to be quite well during this period, see the top panel of Fig. 4.

On the other hand, the match for output dynamics gets poor when compared to data after the PLT period: the significant increase in output is not captured. The relatively large rises in GDP (and industrial production) in the post-PLT period was caused by a variety of factors not present in the model e.g. large changes in government spending and investment due to the increased possibility of a war and significant growth in foreign trade, see Fig. 3 in (Jonung, 1979). The model, on the other hand, describes a closed economy without capital or growth in productivity (and potential output) and has a constant mean of government spending.

\subsection{Sensitivity analysis of model predictions}

The parameters of interest are primarily the preference parameters in the utility function $(\sigma, \varepsilon)$ and the parameter relating to price rigidity $(\gamma)$. Sensitivity analysis of the model with respect to these parameters is now carried out. The adopted ranges for the key utility function parameters are $\sigma=0.5,1,2,3,4$ and $\varepsilon=0.5,0.8,1,2$ while those for $\gamma$ are 42 , 128 and 350 . For $\sigma$, our values are consistent with (Chetty, 2006) who suggests a mean value of 0.7 and maximum values around 3. The parameter $\varepsilon$ governs the Frisch elasticity of labor supply and there is debate surrounding its value. We take a range of values consistent with the recent literature e.g. Chetty et al. (2011), Fiorito and Zanella (2012) and consider values of $\varepsilon$ of $0.5,0.75,1$ and 2 covering ranges of the Frisch elasticity $\left(\varepsilon^{-1}\right)$ from 0.5 to 2 (see also the discussion in section 2.3 of Christiano et al., 2013). As mentioned, the benchmark value of $\gamma=128.21$ assumes an average frequency of price adjustment of about 9.3 months and a markup of 5\%. Using an average frequency of price adjustment of about 14.5 months suggested in Kehoe and Midrigan (2015), (p.37) and a markup of 5\% yields $\gamma=350$ (the latter value is used in Benbabib et al. 2014 and Benbabib et al. 2001). As an alternative, a higher 15\% markup (belonging to an upper range of available empirical estimates; Basu and Fernald, 1997) with average frequency of price changes of 9.3 months yields $\gamma=42$.

Table 2 reports the root mean squared errors (RMSE) between simulated and actual data for the price level, the interest rate and GDP computed over 2.5 years from the adoption of PLT in September 1931. Table 2 uses the value $\gamma=128.21$ and reports the results for the different values of $\sigma$ and $\varepsilon$. Determining the calibration that fits closest to the data from Table 2 is dependent on the criterion. ${ }^{27}$ The sum of the three RMSEs is a possible criterion but $R$ has to be scaled up as $P$

\footnotetext{
25 The standard deviation of output is lower while the autocorrelation of interest rate is higher in the model compared to the data. Appendix E2 provides some further formal statistical evidence that the model and real data of price level and interest rate follow the same process.

${ }^{26}$ In contrast, with the actual policy of constant interest rates there is instability of the low steady state and, so if the policy were maintained for a long time in the model, the economy would most likely experience explosive inflation.

27 RMSE (or root mean absolute error (RMAE)) is a statistical measure and econometricians often use it to judge the fit of out-of-sample forecasting. Here we use this criterion to judge the fit of different calibrations vis- à-vis the data (use of RMAE gives similar results). We multiply the RMSE of $R$ by 100 , which makes the scale comparable to those of $P$ and $y$ and is an approximation of an index number scale.
} 
Table 2

Root Mean Square Errors in price level $P$, output $y$ and normalized interest rate $R$ for the calibration $\gamma=128$.

\begin{tabular}{llllll}
\hline & & $\varepsilon=0.5$ & $\varepsilon=0.75$ & $\varepsilon=1$ & $\varepsilon=2$ \\
\hline$P$ & $\sigma=0.5$ & 0.992551 & 0.891579 & 0.952334 & 1.6614 \\
& $\sigma=1$ & 1.20441 & 1.08501 & 0.989177 & 1.00528 \\
& $\sigma=2$ & 1.50706 & 1.38148 & 1.26713 & 1.03783 \\
\multirow{2}{*}{$R \quad \sigma=3$} & 2.13353 & 2.04289 & 1.90173 & 1.52487 \\
& $\sigma=0.5$ & 0.0667299 & 0.101701 & 0.14864 & 0.303788 \\
& $\sigma=1$ & 0.0696979 & 0.0670699 & 0.0798806 & 0.162435 \\
& $\sigma=2$ & 0.0872422 & 0.0878827 & 0.087326 & 0.10227 \\
$y$ & $\sigma=3$ & 0.127361 & 0.11875 & 0.11593 & 0.103483 \\
& $\sigma=0.5$ & 1.66297 & 1.61673 & 1.57892 & 1.45812 \\
& $\sigma=1$ & 1.50567 & 1.49825 & 1.48445 & 1.44544 \\
& $\sigma=2$ & 1.34993 & 1.35987 & 1.36604 & 1.37644 \\
& $\sigma=3$ & 1.28015 & 1.28769 & 1.28897 & 1.31687 \\
\hline
\end{tabular}

Table 3

Sum of Root Mean Square Errors of Price level $P$, output $y$ and normalized interest rate $R$ for the calibration $\gamma=128$.

\begin{tabular}{llllll}
\hline & & $\varepsilon=0.5$ & $\varepsilon=0.75$ & $\varepsilon=1$ & $\varepsilon=2$ \\
\hline \multirow{2}{*}{ Mum MSE } & $\sigma=0.5$ & 2.72225 & 2.61001 & 2.6798 & 3.42331 \\
& $\sigma=1$ & 2.77978 & 2.65033 & 2.55351 & 2.61316 \\
& $\sigma=2$ & 2.94423 & 2.82923 & 2.7205 & 2.51654 \\
& $\sigma=3$ & 3.54104 & 3.44933 & 3.30663 & 2.94522 \\
\hline
\end{tabular}

and $y$ are measured as index numbers. The best fitting calibration is then $\sigma=\varepsilon=2$ but the benchmark $\sigma=\varepsilon=1$ turns out to be second best and nearly as good, see Table 3 .

RMSE for the calibrations with $\gamma=42$ and 350 are reported in Tables A.1 and A.2 in Online Appendix E3. Briefly, $\gamma=42$ and 128 are generally better than $\gamma=350$ and the benchmark, $\sigma=\varepsilon=1$, continues to perform well with $\gamma=42$. The simulated paths for price level and interest rate have the same qualitative patterns as the actual data across for all of the calibrations during the PLT period as shown in Figs. A.5-A.7 in Online Appendix E3 (see this appendix for further details). Overall, it can be concluded that the NK model with evolving credibility is consistent with the actual Swedish experience of PLT in 1931-1933 during which the economy gradually turned from recession to positive growth.

\section{Conclusions}

Our analysis has two important starting points. The nonlinear global version of a standard framework is used to study the implications of the interest rate lower bound for PLT. Agents have imperfect knowledge so their expectations are not rational during a transition after a shock.

The paper has introduced the domain of attraction of the target steady state in learning dynamics as a new way of assessing of PLT. PLT has been recently suggested as a possible improvement over inflation targeting monetary policy for the current environment with low inflation and low output growth. The results indicate that the performance of PLT is clearly better than inflation targeting, provided private agents' learning has at least partly incorporated the guidance from the price level target path. If private agents' learning does not use the guidance at all, IT has a larger domain of attraction than PLT. Credibility of the PLT regime is important for its success. It is also shown that model simulations with some initial credibility lead to dynamics that are consistent with Swedish experience of price stabilization in1930's.

The current results are a first step in this kind of analysis. Several extensions can be considered. The liquidity trap is sometimes modelled as a shift in the target steady state to ZLB region as a result of a persistent but non-permanent shock to the discount parameter, see (Eggertsson and Woodford, 2003). The general flavor of the results in this paper would probably also hold for this other formulation. Another extension arises from noting that standard policy rules and policy parameters have been used, but these do not represent optimal policies. One could consider optimizing the parameter values of the instrument rules. The comparison of different policy regimes are limited by the assumption that the economy starts in a given IT regime and with given initial expectations. Analyzing how and why private agents might change their forecasting practices after the introduction of a new regime would be worth while.

\section{Supplementary material}

Supplementary material associated with this article can be found, in the online version, at doi:10.1016/j.jmoneco.2019. 09.009. 


\section{References}

Amano, R., Shukayev, M., 2012. Risk premium shocks and the zero bound on nominal interest rates. J. Money, Credit Bank. 44, $1475-1505$.

Basu, S., Fernald, J.G., 1997. Returns to scale in u.s. production: estimates and implications. J. Polit. Econ. 105, $249-283$.

Benhabib, J., Evans, G.W., Honkapohja, S., 2014. Liquidity traps and expectation dynamics: fiscal stimulus or fiscal austerity? J. Econ. Dyn. Control 45, $220-238$

Benhabib, J., Schmitt-Grohe, S., Uribe, M., 2001. The Perils of Taylor Rules. J. Econ. Theory 96, 40-69.

Berg, C., Jonung, L., 1999. Pioneering price level targeting: the swedish experience 1931-1937. J. Monet. Econ. 43, 525-551.

Bernanke, B., 2017. Monetary policy in a new era. In: Peterson Institute Conference on Rethinking Macroeconomic Policy. October 2017

Bodenstein, M., Hebden, J., Nunes, R., 2012. Imperfect credibility and the zero lower bound. J. Monet. Econ. 59, 135-149.

Bostic, R., 2018. Four blogs about price level targeting on march 26-28 and april 2. blogs. www.frbatlanta.org/research/blogs.aspx.

Bullard, J., 2018. Speech: a primer on price level targeting in the U.S. slides. www.stlouisfed.org/from-the-president/speeches-and-presentations.

Bullard, J., Mitra, K., 2002. Learning about monetary policy rules. J. Monet. Econ. 49, 1105-1129.

Camerer, C., 2003. Experimental Game Theory. Princeton University Press, Princeton N.J.

Carney, M., 2012. Speech: guidance. www.bankofcanada.ca.

Chetty, R., 2006. A new method of estimating risk aversion. Am. Econ. Rev. 96, 1821-1834.

Chetty, R., Guren, A., Manoli, D., Weber, A., 2011. Micro versus macro labor supply elasticities. Am. Econ. Rev.: Pap. Proc. 101, 471-475.

Christiano, L., Trabandt, M., Walentin, K., 2013. DSGE models for monetary policy analysis. In: Handbook of Monetary Economics, Vol. 3A, pp. 285-367. Chapter 7

Coenen, G., Wieland, V., 2004. Exchange rate policy and the zero bound on nominal interest rates. Am. Econ. Rev.: Pap. Proc. 94, 80-84.

Curdia, V., Woodford, M., 2010. Credit spreads and monetary policy. J. Money, Credit Bank. 42, S3-S35.

Dennis, R., 2014. Imperfect credibility and robust monetary policy. J. Econ. Dyn. Control 44, 218-234.

Eggertsson, G.B., Woodford, M., 2003. The zero bound on interest rates and optimal monetary policy. Brook. Pap. Econ. Act. 2003 (1), $139-233$.

Eusepi, S., Preston, B., 2018. The science of monetary policy: an imperfect knowledge perspective. J. Econ. Lit. 56, 3-59.

Evans, C.L., 2012. Monetary policy in a low-inflation environment: developing a state-contingent price-level target. J. Money, Credit Bank. 44, 147-155.

Evans, G.W., Honkapohja, S., 2013. Learning as a rational foundation for macroeconomics and finance. In: Frydman, R., Phelps, E.S. (Eds.), Rethinking Expectations: The Way Forward for Macroeconomics. Princeton University Press, Princeton, New Jersey, pp. 68-111.

Fiorito, R., Zanella, G., 2012. The anatomy of the aggregate labor supply elasticity. Rev. Econ. Dyn. 15, $171-187$.

Gali, J., 2008. Monetary policy. Inflation and the Business Cycle. Princeton University Press, Princeton NJ.

Giannoni, M.P., 2014. Optimal interest-rate rules and inflation stabilization versus price-level stabilization. J. Econ. Dyn. Control 41, 110-129.

Gibbs, C.G., Kulish, M., 2017. Disinflations in a model of imperfectly anchored expectations. Eur. Econ. Rev. 100, 157-174.

Jonung, L., 1979. Knut wicksell's norm of price stabilization and swedish monetary policy in the1930's. J. Monet. Econ. 5, 459-496.

Keen, B., Wang, Y., 2007. What is a realistic value for price adjustment costs in new keynesian models? Appl. Econ. Lett. 11, 789-793.

Kehoe, P., Midrigan, V., 2015. Prices are sticky after all. J. Monet. Econ. 75, 35-53.

Kryvtsov, O., Shukayev, M., Ueberfeldt, A., 2008. Adopting price-level targeting under imperfect credibility: an update. Working paper 2008-37, Bank of Canada.

Leeper, E.M., 1991. Equilibria under 'active' and 'passive' monetary and fiscal policies. J. Monet. Econ. 27, $129-147$.

Nakamura, E., Steinsson, J., 2008. Five facts about prices: a reevaluation of menu cost models. Q. J. Econ. 123, 1415-1464.

Rotemberg, J.J., 1982. Sticky prices in the united states. J. Polit. Econ. 90, 1187-1211.

Williams, J.C., 2010. Monetary policy in a low inflation economy with learning. In: Federal Reserve Bank of San Francisco Economic Review, pp. 1-12.

Williams, J.C., 2017. Preparing for the next storm: reassessing frameworks and strategies in a low r-star world. In: FRB Economic Letter 2017-13, pp. 1-8.

Woodford, M., 2003. Interest and Prices: foundations of a Theory of Monetary Policy. Princeton University Press, Princeton, NJ.

Young, H.P., 2004. Strategic Learning and its Limits. Oxford University Press, Oxford UK. 